\title{
Artigos
}

\section{Entre a letra da lei e os desafios da prática: tensões e contradições da Educação Infantil carioca}

Resumo: A formação de professores se insere dentro do tema mais amplo das políticas de infância no Brasil e evidencia relações tensas entre as diretivas legais para o campo da Educação Infantil e a realidade de sua assunção no cotidiano das instituições educativas voltadas para esse segmento. Esse artigo tem como objetivo evidenciar alguns aspectos referentes às políticas de formação docente, expressos nos documentos que a normatizam, como por exemplo, os tempos necessários para planejamento dos professores em exercício e as possibilidades e impossibilidades de sua realização. Partindo da contextualização da história das políticas voltadas para a Educação Infantil, com ênfase na formação do professor, buscamos articular os desafios e tensões presentes na concretização das conquistas legais nas práticas cotidianas das creches e pré-escolas, tomando por meio da investigação de alguns elementos da realidade do Município do Rio de Janeiro.

Palavras-chave: Educação Infantil. Formação de Professores. Políticas Educacionais.

\section{Between the letter of the law and the challenges of practice: tensions and contradictions of Carioca Early Childhood}

Abstract: The training of teachers is part of the broader theme of childhood policies in Brazil and highlights tense relations between the legal directives for the field of Early Childhood Education and the reality of their assumption in the daily life of educational institutions focused on this segment. This article aims to highlight some aspects related to teacher education policies, expressed in the documents that regulate it, such as the time needed for the planning of the teachers in exercise and the possibilities and impossibilities of their realization. With the emphasis on teacher education, we seek to articulate the challenges and tensions present in the achievement of legal achievements in the day-to-day practices of kindergartens and pre-schools, taking the reality of the State of Rio de Janeiro January as the locus of analysis.

Adrianne Ogêda Guedes' Michelle Dantas Ferreira ${ }^{2}$ Edilane Oliveira Da Silva ${ }^{3}$

Keywords: Child education. Teacher training. Education Policy.

\footnotetext{
1 Doutora em Educação pela Universidade Federal Fluminense. Professor Adjunto I da Universidade Federal do Estado do Rio de Janeiro. Coordenadora do grupo FRESTAS de pesquisa. E-mail: adrianne.ogeda@gmail.com

2 Graduada em Pedagogia pela Universidade do Estado do Rio de Janeiro. Diretora Adjunta de uma escola pública da Prefeitura do Rio de Janeiro; Professora de Educação Infantil da Rede Municipal do Rio de Janeiro; Pedagoga e membro do grupo de pesquisa FRESTAS ligado a UNIRIO. E-mail: michaduda@yahoo.com.br

3 Especialista em Educação Infantil pela UFRJ. Graduada em Pedagogia pela Universidade do Estado do Rio de Janeiro. Professora de Educação Infantil da rede Municipal do Rio de Janeiro e membro do grupo FRESTAS de pesquisa, vinculado a UNIRIO. E-mail: laneoliveirasilva@hotmail.com
} 


\section{Educação Infantil, história, memória e políticas}

Se o processo de formação não está aberto à criação, à inovação e à participação dos atores, fica difícil sustentar um conhecimento com sentido para os professores e para as crianças. (KRAMER E NUNES, 2007, p. 445)

\section{Aistória da formação do professor da Educação Infantil no Brasil é razoavelmente recente, pois

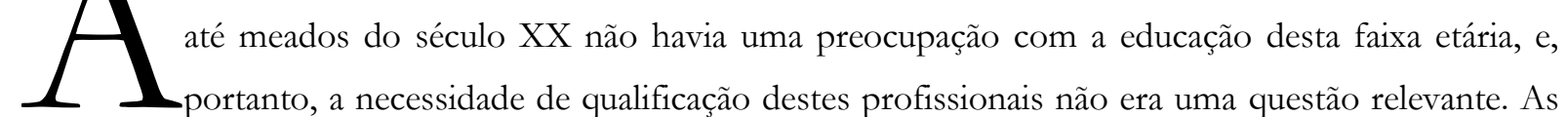 primeiras iniciativas voltadas para a educação da criança de 0 a 6 anos no Brasil são marcadas} por uma perspectiva assistencialista, preparatória e instrumental.

Até a década de 1980 a educação das crianças pequenas no Brasil, era de responsabilidade única e exclusiva das famílias. Esta concepção muda apenas com a constituição de 1988, que em seu Artigo 227 afirma a Educação Infantil como direito da criança. Definindo no artigo 208 como se dará esse oferecimento: “O dever do Estado com a Educação será efetuado mediante a garantia de (...) atendimento em creches e pré-escolas às crianças de zero a seis anos de idade".

A partir da Carta Magna de 1988, as responsabilidades com as crianças pequenas passam a ser, portanto, compartilhadas entre Estado e Família. A partir desta mudança, são pensadas uma série de políticas públicas para esta faixa etária. No entanto, como dito anteriormente, ainda não havia uma especificidade no que dizia respeito à formação dos profissionais para este segmento. Os profissionais ainda eram escolhidos a partir de critérios imprecisos e marcados por uma ideologia de gênero ${ }^{4}$ que consideram ser mãe, ser cuidadosa e gostar de criança como atributos suficientes para a docência 5 .

A contar dos anos de 1990 diversos campos da sociedade se mobilizaram em busca de uma redefinição dos objetivos da Educação Infantil, onde o educar e o cuidar fossem assumidos em sua indissociabilidade 6 e, principalmente, que suas especificidades fossem atendidas, visando o

\footnotetext{
${ }^{4} \mathrm{~A}$ ideologia de gênero diz respeito à ideia de que os dois sexos - masculino e feminino — são construções culturais e sociais e que, portanto, os papéis atribuídos aos gêneros precisam ser problematizados.

${ }^{5}$ Estudos como o de Cerisara (2002) destacam que a identidade profissional da educadora de creche constitui-se no feminino e traz marcas dos processos de socialização das mulheres que, na nossa sociedade, caracterizam-se por identificarem-se com as questões domésticas e a maternagem, características menos valorizadas culturalmente o que, consequentemente se desdobra numa menor valorização de quem trabalha com as crianças pequenas (GUIMARÃES, ARENHART E SANTOS, 2017)

6 Kramer (2003) enfatiza a intrínseca relação entre educar e cuidar, argumentando que a Educação Infantil não pode ser compreendida como uma instância de aprendizagem que só instrui, tampouco como um lugar apenas de guarda e proteção. 0 cuidado com o outro deve se fazer presente no ato de educar, independentemente do nível de ensino em que se está atuando.
} 
desenvolvimento em todas as áreas do conhecimento. Essa foi uma luta que contou, em especial, com as "Universidades e institutos de pesquisa, sindicatos de educadores e organizações não governamentais" (OLIVEIRA, 2002, p.117). Para atender a essas novas demandas, seria necessário a formação de profissionais capacitados, pois não havia mais lugar apenas para assistência ou para "cuidadoras" de crianças, sem um pressuposto educativo.

A Lei de Diretrizes e Bases 9.394/96 (LDB) é um marco principalmente para as questões ligadas a Educação Infantil, que passa a estar sob a responsabilidade da Secretaria Municipal de Educação (SME) no Rio de Janeiro. Além disso, traz reformas, direcionamentos e obrigações em relação a este segmento, e principalmente, metas para a formação dos profissionais. Com a LDB (BRASIL, 1996), a Educação Infantil passou a fazer parte do sistema nacional de ensino, como primeira etapa da Educação Básica, tendo como finalidade o desenvolvimento integral da criança de 0 a 6 anos de idade. Por isso, começa-se a pensar em uma formação específica para os profissionais que nela atuam ou atuarão, bem como a incrementar a discussão sobre a especificidade pedagógica da ação docente voltada para esse segmento (GUIMARÃES, ARENHART E SANTOS, 2017).

No artigo 13 da LDB (BRASIL, 1996, p. 6) são determinadas as seguintes funções do professor da Educação básica:

Participar do planejamento das propostas pedagógicas da Instituição; elaborar e cumprir plano de trabalho de acordo com a proposta pedagógica trabalhada pelo sistema de ensino; zelar pela aprendizagem; cumprir as horas aulas; buscar estratégias para recuperação dos alunos com pouco rendimento e colaborar com atividades de articulação entre a escola e comunidade.

Desta forma, o professor tem funções específicas dentro desta concepção de profissional da Educação Básica. No entanto, o texto não contempla as especificidades do trabalho na Educação Infantil, e consequentemente, das funções deste profissional, principalmente para instituições que possuem especificidades próprias - atendimento em horário integral, necessidades de cuidados e educação para crianças pequenas e bebês.

O artigo 62, da lei supracitada, define que a formação do profissional apto para atuar na Educação Básica:

[...] far-se-á em nível superior, em curso de licenciatura, de graduação plena, em universidades e institutos superiores de educação, admitida, como formação mínima para o exercício do magistério na educação infantil e nos 5 (cinco) primeiros anos do ensino fundamental, oferecida em nível médio na modalidade Normal. (Redação dada pela Lei no 12.796, de 2013).

No entanto, antes da LDB essas formações não abordavam temáticas específicas do cotidiano das instituições educacionais deixando de lado questões como o cuidado e a educação dos bebês ou a proposta pedagógica de escolas de horário integral (MACHADO, 2000). No artigo 63, a lei enfatiza que Institutos Superiores de Educação oferecerão a formação em nível superior para os profissionais, da seguinte forma: 
I - cursos formadores de profissionais para a educação básica, inclusive o curso normal superior, destinado à formação de docentes para a educação infantil e para as primeiras séries do ensino fundamental;

II - programas de formação pedagógica para portadores de diplomas de educação superior que queiram se dedicar à educação básica;

III - programas de educação continuada para os profissionais de educação dos diversos níveis.

O artigo citado acima explicita a necessidade de uma formação em nível superior. Porém, no que se refere à Educação Infantil ainda admitir-se-á a formação em Ensino Médio na modalidade Normal, dando um prazo de dez anos para se adequar à nova legislação.

Arce (2001, p.170) nos mostra que a docência na Educação Infantil foi acontecendo de acordo com a educação que era oferecida, "fortemente impregnada do mito da maternidade, da mulher como rainha do lar, educadora nata", ou seja, sem uma preocupação de fato educativa como a entendida nos dias de hoje, em que se busca efetivar as conquistas legais, os direitos expressos em leis, para que se materializem na prática. Para isso se torna imprescindível conhecer as particularidades desse público, de sua faixa etária, dos profissionais imersos nas instituições e como os direitos garantidos em lei são vivenciados no cotidiano do município do Rio de Janeiro.

As conquistas do campo da Educação Infantil a partir da Constituição Federal e da Lei de Diretrizes e Bases da Educação Nacional (9.394/1996) aqui enunciadas, se afirmam em um conjunto de leis que as acompanham e/ou as sucedem, tais como o Estatuto da Criança e do Adolescente (ECA) (BRASIL, 1990); a Resolução CEB no 1, de 07 de abril de 1999 (BRASIL, 1999) que homologa as Diretrizes Nacionais para a Educação Infantil; a Resolução no 5, de 17 de dezembro de 2009, que fixa as Diretrizes Curriculares Nacionais para a Educação Infantil (DCNEI) (BRASIL, 2009) e a lei de nº 13.257, de março de 2016 (Marco Legal) (BRASIL, 2016) que dispõe sobre as políticas públicas para a primeira infância, para garantir, dentre outros fins, o atendimento profissional devidamente qualificado às especificidades das crianças de 0 a 6 anos:

Art. 10. Os profissionais que atuam nos diferentes ambientes de execução das políticas e programas destinados à criança na primeira infância terão acesso garantido e prioritário à qualificação, sob a forma de especialização e atualização, em programas que contemplem, entre outros temas, a especificidade da primeira infância, a estratégia da intersetorialidade na promoção do desenvolvimento integral e a prevenção e a proteção contra toda forma de violência contra a criança.

Outros tantos documentos que versam sobre as muitas dimensões que envolvem esse atendimento, tais como: "Orientações para a organização da sala na Educação Infantil: ambiente para a criança criar, mexer, interagir e aprender" (SME, 2013) que trata dos espaços físicos; "A avaliação na Educação Infantil" (SME, 2013) que discute a temática que o nomeia; "Planejamento na Educação Infantil: cadernos pedagógicos" (SME, 2011) que discorre sobre a temática do planejar, do registro e das rotinas; "Orientações para profissionais da Educação Infantil" (SME, 2010) que aborda questões relativas ao cuidado, com o ambiente, com a criança e com a comunidade e "Orientações ao Professor de Préescola I e II" (SME, 2013) voltado para a Pré-escola, que apresenta o trabalho com as apostilas e sugere os conhecimentos a serem adquiridos na Educação Infantil nessa modalidade. Esses documentos são 
elaborados pela Secretaria e vêm norteando as práticas na Educação Infantil da Rede Municipal, ao menos na perspectiva do que é desejável alcançar para a qualidade do trabalho desse segmento.

Nesse artigo, cuja ênfase recai sobre as demandas cotidianas do atendimento às crianças da Educação Infantil e da formação em serviço dos professores na realidade vivenciada no município do Rio de Janeiro, daremos destaque a algumas políticas que foram garantidas na teoria, mas que ainda possuem entraves para que se concretizem na prática, como o direito a $1 / 3$ de planejamento garantido pela Lei 11.738 de 2008 em seu Artigo 2 ${ }^{\circ}$, inciso 4', ao determinar que "na composição da jornada de trabalho, observar-se-á o limite máximo de $2 / 3$ (dois terços) da carga horária para o desempenho das atividades de interação com os educandos". Isso é reafirmado pelo Parecer CNE/CEB no 18 de 2012. Com isso, o professor tem $1 / 3$ de seu planejamento destinado a atividades que não envolvam o contato direto com as crianças, podendo cumpri-lo em atividades extraclasse, dentro da instituição, sozinho ou com seus pares. Essa nos parece uma questão central, pois diz respeito a garantia dos espaços para reflexão sobre as próprias práticas, planejamento e organização do trabalho pedagógico, afirmando a necessária intencionalidade pedagógica no contexto educacional.

Outro aspecto que destacamos diz respeito ao excessivo número de crianças por turma neste segmento, pois apesar da existência da Resolução da SME no 1427, de 24 de outubro de 2016 que regulamenta a matrícula, encontramos casos de total discrepância. A diversidade de cargos que diferem em nomenclaturas, carga horária e salário, mas que possuem as mesmas atribuições, causando uma série de tensões entre os profissionais que atuam, muitas vezes juntos, em unidades escolares de Educação Infantil no município do Rio de Janeiro também é um grande nó que necessita ser debatido.

O foco que daremos nas linhas que seguem é apresentar o panorama da situação da rede municipal do Rio de Janeiro no tocante as três grandes questões anunciadas acima, discutindo e tomando a legislação como referência e alguns dos estudos que abordam a temática, sublinhando a sua importância para que a Educação Infantil se consolide como alicerce fundamental para as crianças de 0 a 6 anos. Para embasar a pesquisa, validar nosso interesse pelos pontos escolhidos e sustentar as informações que apresentamos, dialogamos, por meio de questionários aplicados ao final do curso de extensão "Infâncias Cariocas nas creches e pré-escolas: interações e brincadeiras", com um grupo de vinte e nove professores da rede pública de ensino do Rio de Janeiro, que nos permitiram conhecer as especificidades que cada realidade apresenta e a forma como cada uma dessas questões é vivenciada no cotidiano das instituições.

A escolha desses três pontos se deu por sua importância e relevância para o funcionamento das instituições educacionais da rede municipal do Rio de Janeiro como um todo, especialmente na Educação Infantil devido a própria história do seu surgimento e da importância que lhe é atribuída, que diz muito sobre as concepções que o Estado têm acerca da Educação. Além disso, esses foram assuntos que mobilizaram os professores que integraram os cursos de extensão propostos pelo projeto de extensão Infâncias Cariocas, oferecido por um grupo de profissionais ligados ao Núcleo Infância Arte e Natureza (NINA) da Universidade Federal do Estado do Rio de Janeiro (UNIRIO), no primeiro semestre de 2017. Percebendo o quão polêmica e complexa é a realidade da Educação Infantil no município do Rio de 
Janeiro, decidimos nos aprofundar nessas questões, dialogando com a legislação, com autores que abordam o tema, mas sobretudo com os profissionais que atuam cotidianamente nessa realidade.

\section{Pelas Infâncias Cariocas: políticas e direitos na formação docente}

Quanto à formação do professor de educação infantil, tanto a inicial quanto a continuada devem merecer a mesma atenção dispensada à dos demais níveis de ensino. Com isonomia no tratamento administrativo e pedagógico, aliada à urgente valorização profissional, pode-se evitar que as conquistas, ainda que tímidas, consagradas na atual Lei de Diretrizes e Bases da Educação nacional, transformem-se em letra morta. (SALLES E RUSSEF, 2003, p. 90)

Os cursos de extensão de curta duração, denominados "Infâncias Cariocas nas creches e pré-escolas: interaçôes e brincadeiras" foram elaborados no intuito de dar continuidade à proposta de formação docente que já vinha acontecendo, desde 2013, na Faculdade de Educação da Universidade Federal do Estado do Rio de Janeiro (UNIRIO). O Infâncias Cariocas - assim chamado no decorrer de suas aulas - foi composto por três cursos simultâneos: Crianças da Natureza, Lugares do Corpo e Políticas do Cotidiano. Com 32 horas de duração cada, divididas em oito encontros semanais, compondo três turmas de 50 alunos em cada, prevendo um percurso de capacitação e formação docente a 150 profissionais da área da Educação Infantil e áreas afins, entre maio e julho de 2017. Os três cursos foram, prioritariamente, destinados a professoras das redes públicas e conveniadas do Estado do Rio de Janeiro, mas atendendo também, educadores de redes comunitárias, escolas particulares, estudantes e outros profissionais interessados nas questões de educação voltadas à infância (SCHAEFER, TIRIBA E GUEDES, 2017).

As temáticas elegidas interrogavam sobre a macropolítica que mascara a coerção micropolítica cotidiana, aprisionando os corpos e desconectando-os da natureza, em flagrante desrespeito às leis brasileiras, que, por sua vez, embasam e empoderam as lutas que visam uma educação de qualidade para as crianças brasileiras. A metodologia de trabalho dos cursos integrava a garantia permanente de espaços de interlocução em que a palavra circulasse e houvesse compartilhamento de experiências. Nesse sentido, a cada encontro, a temática em foco provocava a que todos os participantes trouxessem aspectos das realidades que vivenciavam, o que nos permitiu compreender mais amplamente as tensões e questões que atravessam o cotidiano de escolas e professores.

Para que pudéssemos compreender como as questões que destacamos nesse artigo se davam na realidade dos integrantes do "Infâncias Cariocas", solicitamos ao final do curso, que respondessem a um questionário cujas questões versavam sobre o $1 / 3$ do planejamento, a lotação de turmas e a multiplicidade de cargos e salários com nomenclaturas e denominações diferentes. Foram enviados um total de cento e cinquenta questionários - entre email e distribuição nas turmas do curso. Porém desse total, tivemos retorno de trinta e três. Para este trabalho selecionamos exclusivamente as respostas dos professores que fazem parte do quadro de funcionários do município do Rio do Janeiro e que atuam diretamente na Educação Infantil. Sendo assim, quatro questionários não foram considerados: dois de professoras da rede privada e dois de graduandas de Pedagogia que ainda não estão trabalhando em instituições escolares. 


\section{O município do Rio de Janeiro e os documentos oficiais: os direitos são garantidos na prática?}

O município do Rio de janeiro se constitui como a maior rede de ensino público da América Latina. Com um total de 1.537 Unidades Escolares divididas em: 1.018 escolas de Ensino Fundamental e 519 Unidades de Educação Infantil, distribuídas em Creches e pré-escolas. São 641.655 alunos matriculados na Rede, sendo 142.884 crianças na Educação Infantil, subdivididos em: 59.776 em Creches e 83.108 em Pré-escolas. Com relação ao corpo docente, possui um total geral de 41.302 professores. Destes, 14.337 são Professores I, 16.824 como Professores II, 4.994 Professores de Ensino Fundamental (PEF) e 5.144 Professores de Educação Infantil (PEI). Há ainda um total de 15.191 funcionários de apoio administrativo, sendo 5.501 Agentes de Educação Infantil.

Devido a seu tamanho, estrutura-se em um nível central que é a Secretaria Municipal de Educação (SME), subdividida em setores denominados Gerências que tratam de assuntos específicos, tais como: Educação, Educação Infantil, Recursos Humanos, Infraestrutura, Mídia, entre outras, e onze Coordenadorias Regionais de Educação (CREs) responsáveis por micro regiões que têm a função de fazer a intermediação entre as propostas da SME e as escolas, com o objetivo de garantir sua concretização e execução nas instituições de ensino.

Antes de nos atermos as especificidades dos fatos e tensões que todo esse tamanho e diversidade geram na Educação Infantil, faz-se necessário explicar as diferentes instituições e as nomenclaturas e funções que cada um desses cargos citados possuem.

Como já foi dito anteriormente, a Educação Infantil é a primeira etapa da Educação Básica e é oferecida em duas modalidades: Creche, para crianças de 0 a 3 anos e 11 meses e Pré-escola, para crianças de 4 a 5 anos e 11 meses. As Creches possuem suas unidades específicas. A Pré-escola, porém, pode ser oferecida em Espaços de Desenvolvimento Infantil (EDI) e Centros Integrados de Educação Pública (CIEPs). O primeiro contempla o atendimento da creche e pré-escola no mesmo espaço físico, sendo definido pela Prefeitura do Rio de Janeiro, por meio de documento específico, como:

[...] um novo modelo público de atendimento à primeira infância e tem como objetivo principal realizar atendimento educativo às crianças entre 3 meses e 5 anos e 6 meses, por meio de uma proposta pedagógica que reconheça e valide a integralidade da criança, isto é, as suas necessidades físicas e de crescimento, psicológicas e emocionais, educativas e cognitivas, assim como seus desejos e interesses. (SME, 2010)

Já os CIEP’s são instituições que têm sua arquitetura tombada e, portanto, não podem sofrer alterações estruturais. Antigamente funcionavam em regime integral, ou seja, as crianças entravam às 7h30min. e saíam às $17 \mathrm{~h}$, fazendo quatro refeições (café da manhã, almoço, lanche da tarde e jantar) e tendo acesso a atividades diversificadas como recreação, Educação Física, Teatro, Dança, Artes, entre outras. Hoje, a grande maioria atua em Turno Único, onde as crianças permanecem por sete horas diárias e fazem três refeições (café da manhã, almoço e lanche). Normalmente, comporta turmas do Ensino Fundamental I, porém alguns ainda conservam turmas de Educação Infantil que não conseguiram ser 
absorvidas pelas EDI's do entorno, seja pela falta de infraestrutura adequada ou pela grande demanda da comunidade local.

No que tange às nomenclaturas e cargos, temos o Professor I, que é aquele habilitado com Licenciatura Plena para lecionar uma disciplina específica (Artes, História, Geografia, Matemática, Português, Ciências, Inglês, Espanhol, Educação Musical e Educação Física) e que pode ter sua carga horária de $16 \mathrm{~h}$ ou $40 \mathrm{~h}$ semanais, dependendo do concurso prestado. Esses profissionais atuam em escolas de Ensino Fundamental II ( $6^{\circ}$ ao $9^{\circ}$ ano), excetuando-se os professores de Educação Física, Artes e Educação Musical que podem atuar da Educação Infantil ao $9^{\circ}$ ano, dependendo das demandas da Rede e de sua lotação.

O Professor II é o habilitado com formação mínima exigida de Ensino Médio na modalidade Normal, para atuar com crianças da Educação Infantil ao $5^{\circ}$ ano do Ensino Fundamental I, que ingressou em concurso anterior ao ano de 2013. Sua carga horária é de $22 \mathrm{~h} 30 \mathrm{~min}$. semanais, podendo atuar em escolas de horário parcial, que possui dois turnos: manhã e tarde. Antes do cargo de Professor de Ensino Fundamental (PEF) este profissional podia também atuar em escolas de horário integral quando possuísse duas matrículas, fizesse Dupla Regência (DR) ou dividindo a turma com outro professor que também fosse PII. Hoje, no entanto, com a criação do cargo de PEF que já tem a carga horária de 40h, esses profissionais foram realocados, em sua maioria, para instituições que funcionam em horário parcial.

O Professor de Ensino Fundamental (PEF) é aquele que tem habilitação de nível superior e que atua do $1^{\circ}$ ao $9^{\circ}$ ano do Ensino Fundamental com carga horária semanal de $40 \mathrm{~h}$. Tanto pode ministrar uma disciplina específica, como já citado anteriormente, quanto atuar com crianças de seis a dez anos, ministrando todas as disciplinas que concernem ao Ensino Fundamental I. A orientação inicial era que esses profissionais fossem lotados em escolas de Turno Único, devido sua carga horária. No entanto, há PEF's lotados em escolas de turno parcial que acabam por fazer uma complementação que equivale a meia Dupla Regência, já que o horário dessas instituições ultrapassam sua carga horária. Existem ainda escolas de turno parcial em que o PEF se recusa a trabalhar além de sua carga horária e essa diferença de cerca de duas horas - do horário de saída do professor que é às $15 \mathrm{~h} 30 \mathrm{~min}$. até o horário de saída da turma que é às 17h30min. - é suprida por membros da Gestão, Professor de Sala de Leitura e/ou Professor de Educação Física e Artes.

O Professor de Educação Infantil (PEI) é o que fez concurso específico para atuar na Educação Infantil (Creche e Pré-escola), tendo como exigência mínima ser habilitado em nível médio modalidade Normal. Sua carga horária pode ser de 22h30min., ou 40h. semanais, dependendo do concurso prestado. Os profissionais que possuem carga horária de $40 \mathrm{~h}$ e atuam em Creches e alguns EDIs que funcionam em horário integral de 9 horas, tem que fazer uma complementação, ou seja, precisam cumprir uma hora a mais todos os dias na Unidade, chegando a $45 \mathrm{~h}$ por semana. Isso acontece por que a carga horária do professor é menor que a permanência das crianças nessas unidades.

Em 2014 foi aberto, para os professores que possuíam carga horária de 22h30min., o processo de migração, que os "converteria" para 40h. Havia uma série de quesitos a serem preenchidos para que 
realmente isso acontecesse. Entre eles: não estar a menos de dez/cinco anos de se aposentar - essa variação se deveu a mudanças no texto no decorrer do processo -; permanecer na mesma Unidade Escolar por mais dez/cinco anos em função de regência, ou seja, sem poder assumir nenhum cargo gratificado (Coordenação ou Gestão) ou por indicação (Sala de Leitura e Recurso); ter feito Dupla Regência em anos anteriores. Além disso, havia prioridade para os profissionais que já atuassem há muitos anos na mesma instituição e que tivessem maior tempo de serviço, exceto aqueles que estivessem próximo da aposentadoria. Com isso, "cria-se" mais uma nomenclatura e um novo tipo de profissional, que é o PII migrado, que passa a ganhar como o PEF - caso tenha nível superior - e ter a mesma carga horária. Porém, difere dele ao poder atuar na Educação Infantil e por ter que cumprir as exigências que o processo de migração impôs.

Algumas dessas especificações podem ser vistas na Lei $n^{\circ} 5623$ de $1^{\circ}$ de outubro de 2013 que dispõe sobre o Plano de Cargos, Carreiras e Remuneração dos funcionários da Prefeitura do Rio de Janeiro, que também apontam as diferenças salariais que esses cargos possuem, mesmo em situações em que a função desempenhada e a carga horária são as mesmas, como é o caso do Professor de Ensino Fundamental (PEF) e o Professor de Educação Infantil de 40h. (PEI), diferindo-se apenas a habilitação mínima exigida no momento do concurso. Ou então, o que consideramos mais grave, a diferença salarial entre o PEF e o PII com duas matrículas. O primeiro tem uma carga horária semanal de 40h. e ganha mais do que o segundo que tem que fazer semanalmente, no total, 45h. Essa diferença também é proveniente da habilitação exigida em concurso, mesmo possuindo as mesmas atribuições no desempenhar das funções.

Ao olharmos somente para a Educação Infantil, foco desse trabalho, percebemos que as contradições estão presentes mesmo nessa micro esfera. Segundo a Resolução da SME no 1427, de 24 de outubro de 2016, as Unidades de Educação Infantil podem ter um funcionamento Integral, em que as crianças passam nove horas diárias na instituição (7h30min. às $16 \mathrm{~h} 30 \mathrm{~min}$.) ou em Turno Único quando a jornada diária for de sete horas (7h30min. às 14h30min.); parcial, com jornada de 4 horas e 30 minutos que pode se dar no período da manhã (7h30min. às $12 \mathrm{~h}$ ) ou da tarde (13h às $17 \mathrm{~h} 30 \mathrm{~min}$.) ou em ambos, quando algumas turmas estão em período integral e outras em horário parcial, dependendo da sua estrutura e da demanda da Comunidade na qual está inserida. Em sua maioria possuem um Diretor Geral, um Diretor Adjunto e em alguns casos, um Professor Articulador, que em Creches e EDI's atua como um Coordenador Pedagógico. Algumas instituições podem ter outro Diretor Adjunto, como é o caso dos CIEP's, mas isso depende do quantitativo total de alunos matriculados. Há ainda nesse espaço os Agentes de Educação Infantil (BRASIL, 2013) que atuam juntamente com o Professor Regente nas turmas. Esse profissional que inicialmente era designado como Agente auxiliar de Creche (BRASIL, 2005) tem como habilitação mínima exigida o Ensino Fundamental completo e sua carga horária é de 40h semanais, sendo $30 \mathrm{~h}$ em atividades em classe e $10 \mathrm{~h}$ em atividades extraclasse: $2 \mathrm{~h}$ em atividades coletivas e $8 \mathrm{~h}$ de atividades individuais. . 
No tocante à composição das turmas, a SME dispôs da Resolução no 1427, de 24 de outubro de 2016, que trata dentre outras coisas, dos critérios para a organização das turmas em todos os segmentos da Educação Básica. Segundo esse documento, a composição das turmas da Creche dar-se-ão da seguinte forma:

1.1.1. As turmas do Berçário serão formadas por 25 (vinte e cinco) crianças na faixa etária de 6 (seis) meses a 1 (um) ano e 11 (onze) meses.

1.1.3. As turmas do Maternal I serão formadas por 25 (vinte e cinco) crianças na faixa etária de 2 (dois) anos a 2 (dois) anos e 11 (onze) meses.

1.1.4. As turmas do Maternal II serão formadas por 25 (vinte e cinco) crianças na faixa etária de 3 (três) anos a 3 (três) anos e 11 (onze) meses.

O documento afirma ainda que quando houver uma demanda maior de crianças a serem matriculadas na instituição, haverá um acréscimo de dez por cento desse total de matrículas em turma, para suprir as necessidades locais. Com isso, as turmas poderão ter no máximo, segundo a Resolução, vinte e oito crianças. Poderá também haver a inclusão de até duas crianças com deficiência e transtorno global do desenvolvimento. Quando isso acontecer, o quantitativo total deverá ser reduzido em duas crianças para cada criança incluída, mas mantendo-se o número de adultos correspondente a vinte e cinco crianças.

As turmas da Educação Infantil na modalidade Pré-escola seguem o mesmo critério de formação. Designa-se Pré-escola I as turmas formadas por crianças de 4 a 4 anos e 11 meses e Pré-escola II as compostas por crianças na faixa etária de 5 a 5 anos e 11 meses. Ambas deverão ter um quantitativo de vinte e cinco crianças, podendo sofrer acréscimo de dez por cento, o que eleva o quantitativo para vinte e oito crianças. A inclusão de crianças com deficiência e transtorno global do desenvolvimento será feita da mesma forma que na Creche, podendo ser incluídas até duas crianças por turma e quando feito, o quantitativo deverá diminuir em dois para cada crianças incluída.

Essa, no entanto, é uma realidade que não acontece na maioria das instituições do município do Rio. Muitas são as Comunidades que contam com poucas instituições de Educação Infantil acabando por não dar vasão ao número de crianças que necessitam de matrícula, principalmente após a alteração da LDB (BRASIL, 1996) feita por meio da Lei no 12.796, de 4 de abril de 2013 que traz obrigatoriedade de matrícula em Unidades Escolares a partir dos quatro anos de idade. O mesmo quadro se dá na Creche, visto que a necessidade de ingresso no mercado de trabalho por parte das famílias se faz cada vez mais crescente, o que leva os responsáveis a procurarem por essas instituições. Em muitos casos, para buscar atender pelo menos o mínimo de quatro horas exigidas por lei (BRASIL, Seção II, Art. 31, 1996), as instituições dividem seu horário em dois turnos, dobrando sua capacidade de atendimento.

Analisando as respostas dos questionários aplicados no grupo de professores do "Infâncias Cariocas", evidenciou-se que todas as turmas encontram-se com quantitativo dentro do estipulado na Resolução, mesmo aquelas que possuem crianças incluídas. No entanto, salientamos que essa é uma amostragem que não reflete necessariamente a condição geral de uma Rede tão grande como a municipal do Rio de Janeiro. Para apurar mais amplamente essa questão, seria necessário um número maior de respondentes. 
O excessivo número de crianças em sala compromete o trabalho do professor que não consegue muitas vezes ter uma atenção individualizada, uma escuta e olhar mais sensível para o que é particular. O educar e cuidar também sofre prejuízos, pois um número maior de crianças demanda mais tempo, o que interfere em toda a rotina da instituição e, consequentemente, no trabalho do professor. Da mesma forma as propostas compartilhadas com as crianças necessitam abarcar o maior número de crianças visto que muitas Unidades não possuem uma estrutura física que comporte, por exemplo, a divisão de variados grupos dentro da mesma sala de aula. Sem contar com a violência do entorno que é um impeditivo para que professores utilizem áreas externas da escola, quando elas existem.

Outra grande polêmica refere-se ao cumprimento do horário de $1 / 3$ para planejamento e outras atividades sem atuação com crianças. Mas o que a legislação fala a respeito desse $1 / 3$ ? Porque é importante que ele seja cumprido?

Segundo a Lei 11.738, de 16 de julho de 2008 , em seu art. $2^{\circ}$, inciso $4^{\circ}$, "na composição da jornada de trabalho, observar-se-á o limite máximo de $2 / 3$ (dois terços) da carga horária para o desempenho das atividades de interação com os educandos". Isso significa que os outros $1 / 3$ destinam-se a atividades extra aulas, definidas no Parecer CNE/CEB no 18/2012 como "horários dedicados à preparação de aulas, encontros com pais, com colegas, com estudantes, reuniões pedagógicas, didáticas [...] necessário[s] para a melhoria da qualidade do ensino e também para a redução das desigualdades regionais". Na prática isso significa que dentre as 40 horas semanais que o professor deve estar com as crianças, 13 horas e 30 min. devem ser utilizadas para planejamento, formação, reuniões e outras atividades sem que o profissional esteja atuando diretamente com elas, o que possibilita que o professor se prepare para o trabalho que realizará com as crianças, pense nas questões que são importantes para o seu grupo, selecione materiais, conheça o acervo da própria instituição, troque com seus pares, tenha um olhar diferenciado e individualizado para as crianças e busque aprimorar seus conhecimentos em formações no próprio espaço escolar.

Infelizmente, sabemos que esse não é um direito consolidado na prática na maioria das instituições públicas de ensino do município do Rio de Janeiro, principalmente naquelas que atendem especificamente ao segmento da Educação Infantil. Ao analisarmos os questionários, pudemos constatar que apenas oito professores atuam em escolas que têm o $1 / 3$ garantido; seis professores não têm esse direito garantido de forma alguma; uma alegou não estar apta a responder por atuar como Agente de Educação Infantil e catorze tem o direito garantido em parte, o que significa dizer que tem um tempo garantido que não é o total estipulado em Lei, mas também não ficam sem tempo nenhum. Pelas respostas percebemos ainda que a maioria consegue garantir um tempo quando a turma está em atividades como Educação Física e Artes, ou sob a regência do Professor Articulador ou Sala de Leitura, o que se aplica apenas para crianças que estão na pré-escola, uma vez que a maioria das Creches não possui esses profissionais.

Essas, no entanto, são medidas que variam de instituição para instituição e de CRE para CRE, pois há Coordenadorias que não disponibilizam, por exemplo, professor de Artes para a Educação 
Infantil, o que interfere nessa organização interna para que se tente garantir o horário de $1 / 3$ de planejamento nessas instituições.

Essas variações indicam disputas de poder entre as CREs e as escolas e demonstram a fragilidade dessa Rede e os contrassensos que a acometem, pois a própria SME, por meio da Circular E/SUBE/CED $\mathrm{n}^{\circ} 11$ de 15 fevereiro de 2012 faz a distribuição dessa carga horária e ainda aponta algumas possiblidades de atividades para serem realizadas com as crianças para que essa proposta se concretize. O que impede então que isso se dê concretamente na prática?

O documento não só reconhece tal direito como organiza o horário com os diferentes parceiros com o objetivo de trocar e enriquecer o planejamento pedagógico. Os parceiros citados são os Agentes de Educação Infantil, que atuam cotidianamente em sala com as crianças e o Professor Articulador, que possui um olhar ampliado em relação à escola. Além de "garantir" algumas horas em que o professor reflete sozinho. Portanto, percebemos que há um olhar para a reflexão sobre o trabalho pedagógico na Educação Infantil, no qual é reconhecida a importância do planejamento com os diferentes parceiros. Mas é fundamental refletirmos sobre as concepções definidas pelo Município acerca de planejamento. A SME, por meio da Gerência de Educação Infantil, formulou um documento denominado Planejamento na Educação Infantil - Cadernos Pedagógicos (SME, 2011), que tem como objetivo guiar as práticas pertinentes a este segmento e apresentar as concepções que orientam o nível central. Nesse documento o planejamento é visto como resultado de um processo reflexivo que norteia a prática e que está vinculado ao registro do trabalho e a observação das crianças de forma individual e coletiva (SME, 2011, p. 11).

O planejamento, então, ganha vida se construído coletivamente. Os educadores que convivem com um grupo de crianças mais de perto têm um olhar voltado para o coletivo e para cada criança em si. Compartilhar essas observações e impressões individuais enriquece o planejamento e o trabalho na Educação Infantil. Os professores articuladores poderão contribuir com um olhar mais amplo, relacionando o Projeto Político Pedagógico (PPP) da instituição com o planejamento da turma. O professor da turma e os Agentes de Educação Infantil (AEI) pensarão em ações para o grupo todo, para pequenos grupos e para algumas crianças em especial, pois é necessário que esse planejamento atinja a todos e a cada um, visando proporcionar às nossas crianças um ambiente acolhedor, alegre e sereno, com condições favoráveis de aprendizagem. (Circular E/SUBE/CED n 11, 2012)

Observamos que para que esse planejamento se concretize é fundamental o encontro, as reflexões e ações, lembrando que no ano de 2012, quando a circular foi publicada, enfatizava que aos poucos esse direito seria "gradativamente ampliado de acordo com a disponibilidade de recursos humanos da rede" (Circular E/SUBE/CED n. 11, 2012, p.1). Hoje, no ano de 2017, temos uma situação ainda muito próxima do que tínhamos em 2012, já que tais direitos ainda não são assegurados na prática pela rede.

\section{Considerações finais}


O presente trabalho refletiu sobre como a letra da lei se materializa ou não, nas práticas de professores que fazem parte do município do Rio de Janeiro. Ao pensarmos na história da profissionalização deste docente, pudemos constatar o quão complexa se apresentou, especialmente no que diz respeito às garantias de alguns direitos adquiridos, mas que de fato não estão concretizados na rede do Rio de Janeiro.

Ao ouvirmos os professores a respeito de $1 / 3$ do planejamento observamos o quanto às leis que garantem no papel as conquistas descritas no artigo estão bem distantes do que acontece no chão da escola. Algumas instituições, porém, conseguem assegurar e contemplar aos professores que lá atuam, seu direito pleno. Diante dessa diversidade presente nas respostas aos questionários, que refletem as diferentes realidades possíveis dentro de uma mesma rede, pensamos no porquê e no como. Porque algumas Unidades conseguem, e outras não? Como garantir esse direito a todas?

Nesse contexto se mostra fundamental a garantia de espaços para que as atividades extraclasses aconteçam, favorecendo assim a reflexão individual desse professor e aquela que acontece quando ele está com seus pares, voltada para as práticas referentes à Educação Infantil, pois acreditamos que desta maneira possamos construir juntos um entendimento coletivo das nossas especificidades. Além disso, fazse urgente que o Munícipio do Rio de Janeiro busque estratégias que possam garantir os direitos dos profissionais da educação para que assim seja construída uma educação de qualidade, que valorize a formação e respeite as conquistas legais adquiridas.

O respeito à legislação que garante um tempo adequado para que o professor planeje e se forme, a organização de turmas que tenham o quantitativo determinado pelas Portarias e Resoluções e um plano de cargos e salários justo e coerente é uma forma de valorização da Educação Infantil e do profissional que nela atua, assim como dos outros segmentos. É um direito adquirido que contribui para a melhoria das condições de trabalho e num fazer pedagógico que tem um investimento maior, de tempo, reflexão, estudo e elaboração.

\section{Referências Bibliográficas}

ARCE, Alessandra. Documentação oficial e o mito da educadora nata na educação infantil. Caderno de Pesquisa, São Paulo, n. 113, jul. 2001.

BIZZO, Kátia; TIRIBA, Léa; GUEDES, Adrianne Ogêda. Infâncias Cariocas: Corpo, Conexão com a Natureza e Empoderamento Político. Trabalho apresentado no Seminário Fala Outra Escola, Campinas/SP, 2017.

BRASIL. Constituição (1988). Constituição da República Federativa do Brasil. Brasilia: Senado, 1988. . Lei no 8.069 de 13 de julho de 1990. Dispõe sobre o Estatuto da Criança e do Adolescente e dá outras providências. Diário Oficial da União, Brasília, 16 jul. 1990. 
Lei no 9.394 de 20 de dezembro de 1996. Estabelece as diretrizes e bases da educação nacional. Diário Oficial da União, Brasilia, 23 dez. 1996.

Lei no 3985 de 8 de abril de 2005. Cria no Quadro Permanente do Poder Executivo do Município do Rio de Janeiro a categoria funcional que menciona e dá outras providências. Diário Oficial do Município, Rio de Janeiro, 12 abr. 2005.

Lei n 5623 de 1 de outubro de 2013. Dispõe sobre o Plano de Cargos, Carreiras e Remuneração dos funcionários da Secretaria Municipal de Educação e dá outras providências. Diário Oficial do Município, Rio de Janeiro, 2 out. 2013.

Lei no 11.738 de 16 de julho de 2008. Regulamente a alínea "e" do Inciso III do caput do art. 60 do Ato das Disposições Constitucionais Transitórias, para instituir o piso salarial profissional nacional para os profissionais do magistério público da educação básica. Diário Oficial da União, Brasília, 17 jul. 2008.

Lei no 12.796 de 4 de abril de 2013. Altera a Lei no 9.394, de 20 de dezembro de 1996, que estabelece as diretrizes e bases da educação nacional, para dispor sobre a formação dos profissionais da educação e dar outras providências. Diário Oficial da União, Brasília, 5 abr. 2013.

Lei n 13.257 de 8 de março de 2016. Dispõe sobre as políticas públicas para a primeira infância e altera a Lei no 8.069, de 13 de julho de 1990 (Estatuto da Criança e do Adolescente), o DecretoLei no 3.689, de 3 de outubro de 1941 (Código de Processo Penal), a Consolidação das Leis do Trabalho (CLT), aprovada pelo Decreto-Lei n ${ }^{\circ}$ 5.452, de $1^{\circ}$ de maio de 1943, a Lei ${ }^{\circ} 11.770$, de 9 de setembro de 2008, e a Lei no 12.662, de 5 de junho de 2012. Diário Oficial da União, Brasília, 9 mar. 2016.

Ministério da Educação. Secretaria de Educação Básica. Diretrizes Curriculares Nacionais para a Educação Infantil. Brasília: MEC/SEB, 2010.

Ministério da Educação. Conselho Nacional de Educação. Resolução CEB nº 1, de 7 de abril de 1999. Institui as Diretrizes Curriculares Nacionais para a Educação Infantil. Diário Oficial da União, Brasília, 13 abr. 1999.

Ministério da Educação. Conselho Nacional de Educação. Parecer CEB no 18, de 2 de outubro de 2012. Trata da implementação da Lei n ${ }^{\circ} 11.738$ de 2008, que institui o piso salarial profissional nacional para os profissionais do magistério público da Educação Básica. Diário Oficial da União, Brasília, 1 ago. 2013.

Ministério da Educação. Conselho Nacional de Educação. Resolução no 5, de 17 de dezembro de 2009. Fixa as Diretrizes Curriculares Nacionais para a Educação Infantil: Brasília: MEC/CNE, 2009. 
GUIMARÃES, Daniela Oliveira; ARENHART, Deise; SANTOS, Núbia Oliveira. Educação Infantil Pós LDB/96: identidade docente e formação de professores. Revista Contemporânea de Educação, UFRJ/Rio de Janeiro, vol. 12, n. 24, maio/ago. 2017.

KRAMER, Sonia; NUNES, Maria Fernanda. Gestão pública, formação e identidade de profissionais de Educação Infantil. Cadernos de Pesquisa, São Paulo, vol. 37, n. 131, p. 423-454, maio/ago. 2007.

MACHADO, Maria Lúcia de Almeida. Desafios iminentes para projetos de formação de profissionais para educação infantil. In: Cadernos de Pesquisa nº 110. São Paulo: Cortez, 2000.

OLIVEIRA, Zilma Moraes Ramos. Educação Infantil: fundamentos e métodos. São Paulo: Cortez, 2010. (Coleção docência em formação).

SALLES, Fernando Casadei; RUSSEFF, Ivan. Formação continuada do professor de educação infantil e identidade profissional. In: RUSSEFF, Ivan; BITTAR, Mariluce (Orgs.). Educação Infantil: política, formação e prática docente. Brasília-DF: Editora Plano/UCDB, vol. I, 2004.

SECRETARIA MUNICIPAL DE EDUCAÇÃO. A avaliação na Educação Infantil. Rio de Janeiro, jul. 2013.

Espaço de Desenvolvimento Infantil (EDI): modelo conceitual e estrutura. Rio de Janeiro, fev. 2010.

Orientações para a organização da sala na Educação Infantil: ambiente para a criança criar, mexer, interagir e aprender. Rio de Janeiro, mar. 2013.

Orientações para profissionais da Educação Infantil. Rio de Janeiro, jul. 2010.

. Orientações ao Professor de Pré-escola I e II. Rio de Janeiro, 1º semestre de 2013.

Planejamento na Educação Infantil. Cadernos Pedagógicos, vol. I, Rio de Janeiro, fev. 2011.

Resolução no 1427, de 24 de outubro de 2016. Dispõe sobre a estrutura de atendimento, organização de turmas, horário de funcionamento e Matriz Curricular das Unidades Escolares da Rede Pública de Ensino da Cidade do Rio de Janeiro, e dá outras providências. Diário Oficial do Município, Rio de Janeiro, 26 out. 2016.

Circular E/SUBE/CED no 11, de 15 de fevereiro de 2012. Dispõe sobre horário Extraclasse Semanal para os profissionais da Educação Infantil - Informações complementares AAC e PEI. 